\title{
Too Passive to Prevent Ventilator-Associated Pneumonia
}

Ventilator-associated pneumonia (VAP) is a common complication of patients receiving invasive mechanical ventilation support. VAP continues to be associated with high morbidity, mortality, hospital cost $(\$ 10,000$ to $\$ 25,000$ ) and ICU stay. ${ }^{1}$ Depending on the definition used, the VAP rate ranges from 1.2 to 8.5 cases per 1,000 ventilators days. ${ }^{2}$ Prevention of complications and patient safety is currently a priority in the United States healthcare administration, and VAP is proposed as a quality-of-care indicator and a preventable disease. A rate of zero VAP has been encouraged and reported using the National Healthcare Safety Network. ${ }^{3}$ However, the importance of this zero rate remains unclear, especially when external pressure to report a low VAP rate and to limit reimbursement might be present. ${ }^{4}$ Therefore, initiatives that may prevent VAP and can consistently sustain successful results are matters of great interest for patients, families, healthcare provides, and healthcare systems.

\section{See the Original Study on Page 1582}

Multiple pharmacologic and non-pharmacologic strategies have been shown to prevent VAP. ${ }^{5}$ Most of these strategies are focused on preventing the pathophysiology associated with VAP. The 2 most important mechanisms involved in the development of VAP are microaspiration and biofilm formation. ${ }^{6}$ Microaspiration is the major route for oropharyngeal secretions to migrate distally around the endotracheal tube (ETT) cuff. ${ }^{7}$ Both the stomach and ETT have been proposed as potential reservoirs for infecting microorganisms. In addition, the ETT may act as a bridge between the oropharyngeal environment and the sterile bronchoalveolar space, thus bypassing the host defenses. ${ }^{7,8}$ Evidence-based practice guidelines recommend to bundle several interventions in order to prevent VAP, as suggested by the Institute for Healthcare Improvement ventilator bundle. When the VAP bundle is not able to achieve a zero VAP rate, then other interventions are suggested, such as focusing on preventing microaspiration by using one of the newer technological advances in ETTs. ${ }^{6-8}$ However, there are limited data from real world or clinical effectiveness studies using newer ETT technologies.

In this issue of Respiratory CARE, Bowton et al report a clinical effectiveness study on a 2-period, investigator- initiated observational analysis on 2,849 mechanically ventilated patients. ${ }^{9}$ The authors evaluated the efficacy of tapered-cuff ETTs in reducing the VAP rate. ${ }^{9}$ The mean monthly VAP rate in the tapered-cuff ETT was $2.77 \pm 2 /$ 1,000 ventilator days, compared to $3.29 \pm 1.79 / 1,000$ ventilator days in the standard barrel-cuff ETT group $(P=.65) .{ }^{9}$ In addition, adherence to the VAP prevention bundle was higher during the use of standard barrel-cuff ETT group (96\%), versus $90 \%$ in the tapered-cuff ETT group $(P=.01)$. Failure to adhere to oral care was the most common VAP bundle non-adherence issue in the study by Bowton et al. ${ }^{9}$ Therefore, the authors conclude that the use of a tapered-cuff ETT was not associated with a reduction of VAP rates. The findings of this study deserve further consideration, and it is important to recognize the hospital-wide effort to stop a preventable condition, such as VAP.

The implementation of a new intervention in $110 \mathrm{ICU}$ beds of 6 ICUs is a major investment for a hospital system, because these newer ETTs are more expensive than the standard ETT. However, the cost-benefit ratio of preventing one VAP could favor this investment. In addition, the achievement of an adherence rate above $90 \%$ with the VAP bundle suggests that, despite substantial efforts to consistently elevate the head of the bed, perform oral care and maintain oral hygiene, and place orogastric tubes for feeding instead of nasogastric tubes, there is a need to do something else to prevent VAP. This issue and the unacceptable high rate of VAP are the main motivations to invest in and implement a new ETT in the hospital setting. It is interesting that the results from this study differ from previous in vitro and clinical studies, which confirmed the benefits of using a tapered-shaped cuff ETT that prevents fluid leakage, compared to the cylindrical-shaped cuff ETT. ${ }^{10,11}$ This prevention of fluid leaking past the ETT cuff results in the reduction of early postoperative pneumonia in patients undergoing cardiac surgery. ${ }^{12}$ In the study by Bowton et al the large pre- and post-intervention sample size is very high, compared to prior randomized control trials; however, the low VAP rate, at least, makes this study difficult to compare to prior studies with a much higher rate of VAP (10-15/1,000 ventilator days).,59

Why is the study by Bowton et al negative? Several questions and hypothesis are derived by this interesting pre- and post-observational study. First, the use of a "passive" intervention, such as the one proposed with the 
tapered-shaped cuff ETT that prevents fluid leak, might not be enough to fully prevent the development of VAP. This is why the newer version of the product and the additional ability to suction the subglottic secretions do not only prevent the secretions from passing the ETT, but allow a method of removing them from the subglottic area. The use of subglottic secretion drainage has been extensively evaluated in the literature, with the strongest success rate for preventing early and late VAP. ${ }^{13}$ Therefore it is possible that, by using the newer Seal Guard ETT technology, a further reduction of VAP may be achieved. Second, the rate of VAP in the standard group was 3.29 VAPs per 1,000 ventilator days, which happens to be much lower than the baseline institutional monthly VAP rate of 5.8 per 1,000 ventilator days. ${ }^{9}$ This difference suggests that the VAP bundle adherence may have played a critical role in reducing the VAP rate. It is possible that an almost perfect (96\%) VAP bundle adherence might have dropped the rate from 5.8 to 3.3 before starting the implementation with the tapered-shaped cuff ETT.

This is very important, because starting from a much lower VAP rate may have made it even more difficult to achieve a statistically significant difference after the intervention implementation. However, we applaud the honesty and professionalism of the authors for recognizing and publishing a non-zero VAP rate. These results suggest that the heterogeneity of the different ICUs, combining medical, surgical, neurointensive, cardiothoracic, and coronary ICUs, may limit the impact of the new ETT. Neurointensive and trauma ICUs have higher rates of VAP, due to circumstances such as endotracheal intubation and gross aspiration, which make it difficult to fully prevent the risk of VAP. Additionally, the consideration that patients with contraindications for VAP bundle adherence should be considered as adherent to all the bundle components bias the results, due to the failure to institute strategies in certain patients. ${ }^{13}$ This creates the possibility that, indeed, there are groups of patients in whom no VAP preventive strategies were used, which could perfectly explain the inability to generalize these results to all the patients who require mechanical ventilation.

How will this study influence or change my practice? It is very encouraging that by adopting good adherence rates with the VAP bundle, a VAP rate of 3 per 1,000 ventilator days can be achieved. However, in order to en-

\footnotetext{
The authors have disclosed no conflicts of interest.

Correspondence: Marcos I Restrepo MD MSc, Division of Pulmonary Diseases and Critical Care, University of Texas Health Science Center at San Antonio, 7400 Merton Minter Street, MC 111E, San Antonio, TX 78229. E-mail: Restrepom@uthscsa.edu.
}

DOI: $10.4187 /$ respcare. 02803 hance the effect of a lower VAP rate it is important to consider other proven strategies, such as the implementation of new ETT technologies. The evidence suggests that ETTs that suction subglottic secretions may have the strongest effect in preventing VAP. Therefore, each physician, practice, hospital, or ICU should evaluate their VAP rate and VAP adherence before considering other ETT technologies.

Juan Felipe Fernandez MD

Division of Pulmonary Diseases and Critical Care University of Texas Health Science Center at San Antonio San Antonio, Texas

Marcos I Restrepo MD MSc Division of Pulmonary Diseases and Critical Care University of Texas Health Science Center at San Antonio and

Audie L Murphy Division South Texas Veterans Health Care System and Evidence Based Research Dissemination and Implementation Center San Antonio, Texas

\section{REFERENCES}

1. Shorr AF, Zilberberg MD, Kollef M. Cost-effectiveness analysis of a silver-coated endotracheal tube to reduce the incidence of ventilator-associated pneumonia. Infect Control Hosp Epidemiol 2009;30(8): 759-763.

2. Skrupky LP, McConnell K, Dallas J, Kollef MH. A comparison of ventilator-associated pneumonia rates as identified according to the National Healthcare Safety Network and American College of Chest Physicians criteria. Crit Care Med 2012;40(1):281-284.

3. Dudeck MA, Horan TC, Peterson KD, Allen-Bridson K, Morrell G, Pollock DA, Edwards JR. National healthcare safety network (NHSN) report, data summary for 2010 device-associated module. Am J Infect Control 2011;39(10):798-816.

4. Klompas M. Is a ventilator-associated pneumonia rate of zero really possible? Curr Opin Infect Dis 2012;25(2):176-182.

5. Maselli DJ, Restrepo MI. Strategies in the prevention of ventilatorassociated pneumonia. Ther Adv Respir Dis 2011;5(2):131-141.

6. Fernandez JF, Levine SM, Restrepo MI. Technologic advances in endotracheal tubes for prevention of ventilator-associated pneumonia. Chest 2012;142(1):231-238.

7. Chastre J, Fagon JY. Ventilator-associated pneumonia. Am J Respir Crti Care Med 2002;165(7):867-903.

8. Dezfulian C, Shojania K, Collard HR, Kim HM, Matthay MA, Saint S. Subglottic secretion drainage for preventing ventilator-associated pneumonia: a meta-analysis. Am J Med 2005;118(1):11-18.

9. Bowton DL, Hite RD, Martin RS, Sheretz R. The impact of hospitalwide use of a tapered cuff endotracheal tube on the incidence of ventilator-associated pneumonia. Respir Care 2013;58(10):15821587. 
Too Passive to Prevent Ventilator-Associated Pneumonia

10. Dave MH, Frotzler A, Spielmann N, Madjdpour C, Weiss M. Effect of tracheal tube cuff shape on fluid leakage across the cuff: an in vitro study. Br J Anaesth 2010;105(4):538-543.

11. Lucangelo U, Zin WA, Antonaglia V, Petrucci L, Viviani M, Buscema G, et al. Effect of positive expiratory pressure and type of tracheal cuff on the incidence of aspiration in mechanically ventilated patients in an intensive care unit. Crit Care Med 2008; 36(2):409-413.
12. Poelaert J, Depuydt P, De Wolf A, Van de Velde S, Herck I, Blot S. Polyurethane cuffed endotracheal tubes to prevent early postoperative pneumonia after cardiac surgery: a pilot study. J Thorac Cardiovasc Surg 2008;135(4):771-776.

13. Muscedere J, Rewa O, McKechnie K, Jiang X, Laporta D, Heyland DK. Subglottic secretion drainage for the prevention of ventilatorassociated pneumonia: a systematic review and meta-analysis. Crit Care Med 2011;39(8):1985-1991. 